\title{
Effect of Automotive Gas Oil (AGO) on Geotechnical Properties of Lateritic Soil
}

\author{
Akaninyene O. Akankpo \\ Department of Physics, University of Uyo, Uyo, Akwa Ibom State, Nigeria \\ Emmanuel B. Umoren \\ Department of Physics, University of Uyo, Uyo, Akwa Ibom State, Nigeria
}

\begin{abstract}
Environmental pollution from petroleum and petrochemical products has been recognized as one of the most serious problems associated with accidental spills on a large scale. This study was carried out to investigate the effect of automotive gas oil (ago) on geotechnical properties of lateritic soil. Test carried out included Optimum Moisture Content, Maximum Dry Density, Sieve Analysis, Liquid Limits, Plastic Limits, Plasticity Index, Specific Gravity and Unconfined Compressive Test. Certain percentages of AGO (0 \%, $4 \%, 8 \%, 12 \%, 16 \%)$ were mixed with the lateritic soil sample. Based on the results obtained, Optimum Moisture, Maximum Dry Density, specific gravity and unconfined compressive test decreased as the percentage of automotive gas oil (AGO) increased, while Atterberg limits and Sieve analysis increased as the percentage of automotive gas oil (AGO) increased. Addition of AGO to the soil led to the reduction of porosity and permeability resulting from the entrapment of the AGO within the pore spaces of the soil.
\end{abstract}

Keywords: Automotive Gas Oil, Geotechnical Properties, Lateritic Soil, Contaminants

DOI: $10.7176 /$ APTA/82-03

Publication date: January $31^{\text {st }} 2020$

\section{Introduction}

Rapid industralisation and human activities leading to the generation and disposal of chemical and toxic waste materials have given birth to the continuous contamination of surface and subsurface environments. Environmental pollution from petroleum and petrochemical products has been recognized as one of the most serious problems associated with accidental spills on large scale (Jesna and Hari 2015). Hydrocarbon leaks and spills have become a great concern in most of the oil producing countries of the world. Amongst the contaminants, hydrocarbon derivatives are a major source of soil pollution; petrol and diesel being the chief contributors.

Oil Contaminated Soil (OCS) has been defined by Colorado Department of Health and Environment (2003), as any earthen material or artificial fill that has human or natural alteration of its physical, chemical, biological or radiological integrity resulting from the introduction of crude oil, any fraction or derivative (such as gasoline, diesel or used motor oil) or any oil based product. The production, dumping and pollution of oil waste wreak havoc on the surrounding wildlife and habitat.

The hydrocarbon contamination does not only affect the quality of the soil but also alter the physical properties of the oil-contaminated soil. This may lead to geotechnical problems related to construction or foundation of structures on the oil-contaminated site (Jesna and Hari, 2015).

According to Afolabi et al (1985), the 1972 Environmental Impact Statement had singled out oil as being the greatest threat to the environment. In Nigeria, the exploration of petroleum, liquid waste from automobile mechanic workshops, industrial wastes, palm oil market activities and other oil related human activities contribute to indiscriminate oil spillages. Oil spillage could take place in water or land. On land, the degree of oil pollution depends on a number of factors which include the permeability of the soil, absorption properties of the soil and the partition coefficient (Al-Sanad et al, 1995). The extent of contamination depends on the chemical composition of the contaminants and properties of the soil. Hydrocarbon pollution of soil occurs in several ways, from natural seepage of hydrocarbon in areas where petroleum is found in shallow reservoir to accidental spillage of oil on the ground (Onyelowe, 2015).

Researches have been carried out on the effects of hydrocarbon spillage, waste engine oil pure crude oil on the geotechnical properties of various types of soil. Jesna and Hari (2015) investigated the effect of hydrocarbon spillage on soil properties and concluded that diesel contaminated soil samples have adverse effects on the geotechnical properties of the soil. He found that the liquid limit, plastic limit, strength and permeability of the soil decreased as the diesel content increased. Rahman (2010) observed that oil-contaminated soils indicated a lower Maximum Dry Density (MDD) and optimum water content compared with uncontaminated soils. According to Onyelowe (2015), increase in crude oil contamination causes changes in the properties of the soil. From $0 \%$ crude oil contamination, the void ratio decreased with increase in crude oil contamination which also affected the compression index of the soil. The Atterberg limit examination indicated that the crude oil contamination affected both the bonding between the soil particles and the fluidity of the entire mixture. Alhassan and Fagge (2013) 
studied the effects of crude oil, low pour fuel oil and vacuum gas oil contamination on the geotechnical properties of sand, clay and lateritic soils and concluded that the shear strength of sand and laterite increased with used engine oil contamination. In a similar investigation, Ijimdiya (2013) concluded that oil contamination leads to decrease in the Unconfined Compressive Strength (UCS), coefficient of consolidation and coefficient of volume compressibility up to $6 \%$ oil content. In a related study carried out by Otunyo and Anele (2015), it was observed that the specific gravity and plastic limits of oil contaminated soil decreased as the content of used engine oil increased.

In this study, our aim is to determine the effects of Automobile Gas Oil (AGO) on the geotechnical properties of lateritic soil in Uyo, Nigeria.

\section{Methodology}

Lateritic soil samples were collected at Use Offot, Uyo, at the depth of about I metre below the ground surface. The soil samples were divided into five portions and each portion was mixed with $(0 \%, 4 \%, 8 \%, 12 \%$ and $16 \%)$ of automobile gas oil, measured by dry weight of the soil (Otonyo and Anele, 2015). These samples were stored in airtight plastic containers before being air-dried at room temperature for fourteen (14) days. Various tests such as Atterberg limits, compaction test, particle size distribution (sieve analysis), unconfined compression and specific gravity were carried out. These tests were performed on the uncontaminated $(0 \%$ automotive gas oil content) and the contaminated $(4 \%, 8 \%, 12 \%$ and $16 \%$ automotive gas oil content) soil samples respectively. Some of the geotechnical parameters obtained in this study are presented in Table 1.

\section{Results and Discussion}

Table 1 contains some geotechnical parameters obtained in this work. The sample has the highest value of optimum moisture content (OMC) of $13.44 \%$ at $0 \%$ Automotive Gas Oil (AGO). The value of optimum moisture content decreased as the percentage of AGO increased. The least value of $10.81 \%$ was obtained at $16.00 \%$ AGO (Figure 1). The maximum dry density reduced as the percentage of contamination increased. At $0 \%$ of AGO, the value of maximum dry density was $1.83 \%$, while the least value of maximum dry density of $1.69 \%$ corresponded to $16 \%$ of AGO (Figure 2).

Table 1: Summary of Geotechnical Parameters and Percentages of AGO

\begin{tabular}{|l|l|l|l|l|l|}
\hline \multirow{2}{*}{ Tests } & \multicolumn{5}{|c|}{ Percentages of Automobile Gas Oil (AGO) } \\
\cline { 2 - 6 } & $\mathbf{0 \%}$ & $\mathbf{4 \%}$ & $\mathbf{8 \%}$ & $\mathbf{1 2} \%$ & $\mathbf{1 6} \%$ \\
\hline Optimum Moisture Content (OMC) (\%) & 13.44 & 13.38 & 13.33 & 13.27 & 10.81 \\
\hline Maximum Dry Density (MDD) (\%) & 1.83 & 1.76 & 1.72 & 1.70 & 1.69 \\
\hline Sieve Analysis(mm) & 33.40 & 38.96 & 39.00 & 42.80 & 44.43 \\
\hline Liquid Limits (\%) & 34.00 & 37.00 & 38.00 & 40.00 & 42.00 \\
\hline Plastic Limits (\%) & 23.00 & 24.00 & 24.00 & 25.00 & 26.00 \\
\hline Plastic Index (\%) & 11.00 & 13.00 & 14.00 & 15.00 & 16.00 \\
\hline Specific Gravity (\%) & 2.61 & 2.24 & 2.19 & 2.17 & 2.14 \\
\hline Unconfined Compressive Test Kn/m2 & 189.68 & 123.27 & 89.34 & 84.16 & 75.40 \\
\hline
\end{tabular}

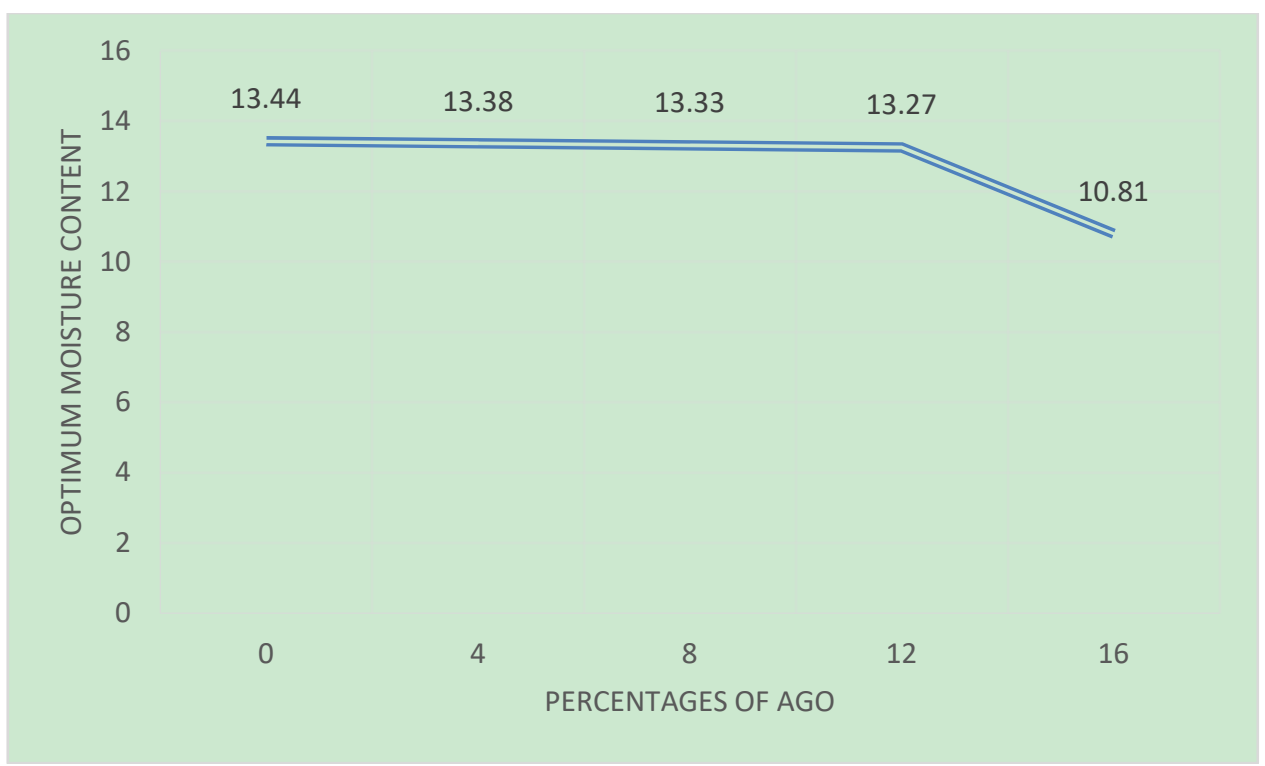

Figure 1: Graph of Optimum Moisture Content against Automotive Gas oil 


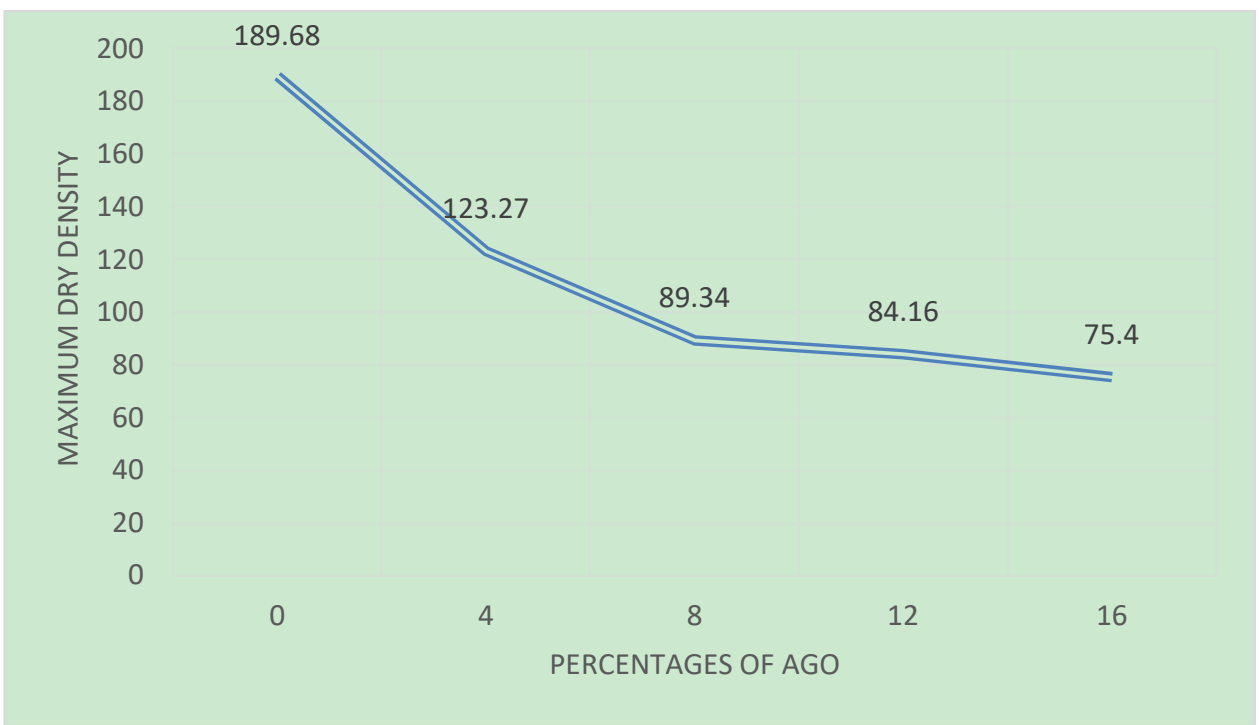

Figure 2: Graph of Maximum Dry Density against Automotive Gas oil

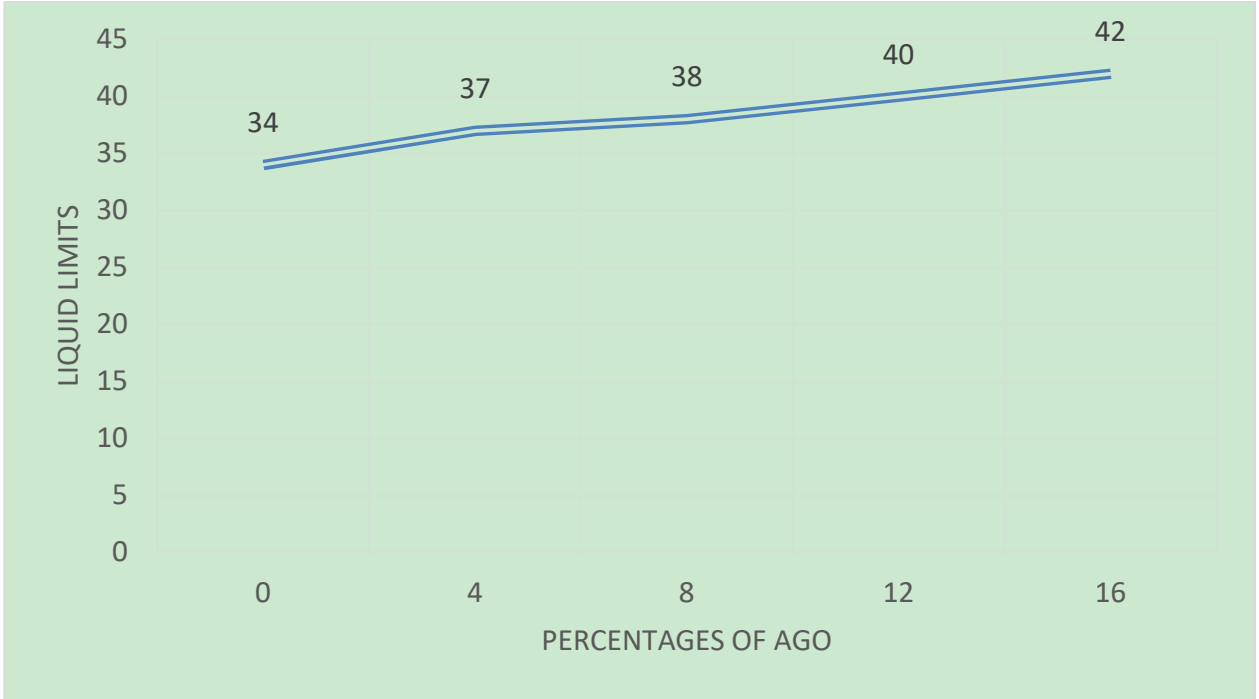

Figure 3: Graph of Liquid Limits against Automotive Gas oil

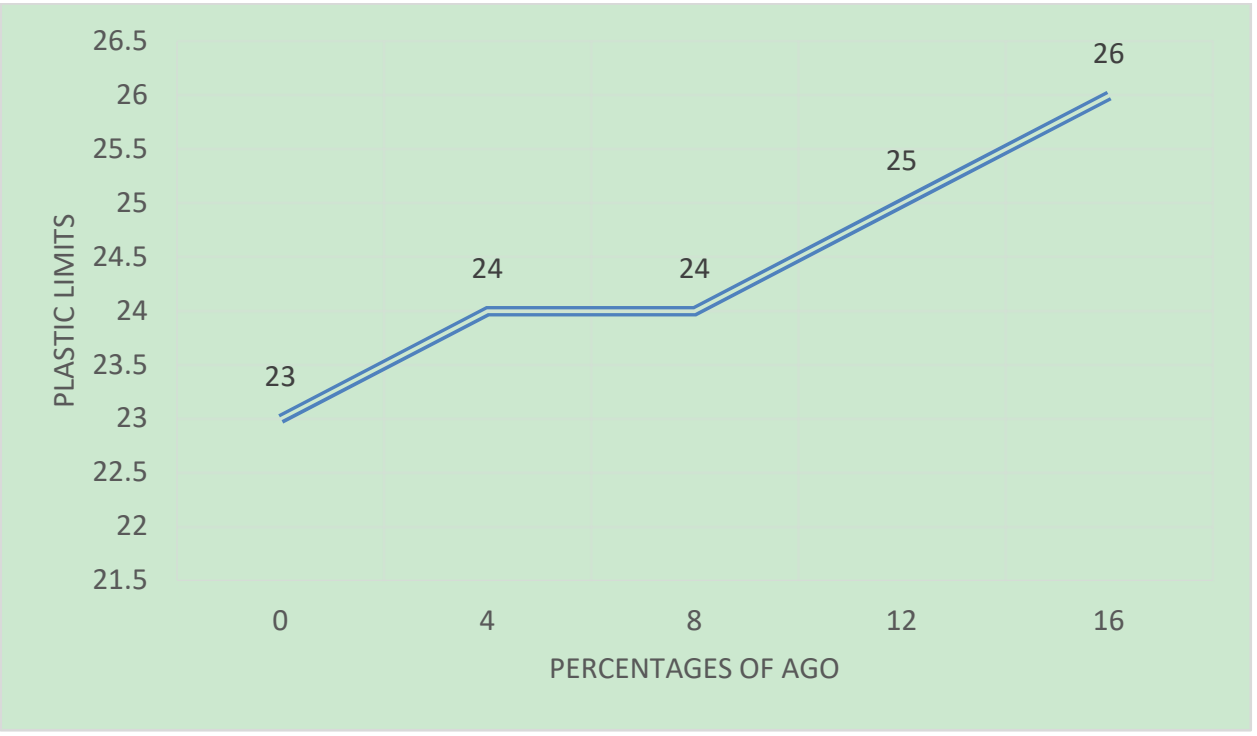

Figure 4: Graph of Plastic Limits against Automotive Gas oil 


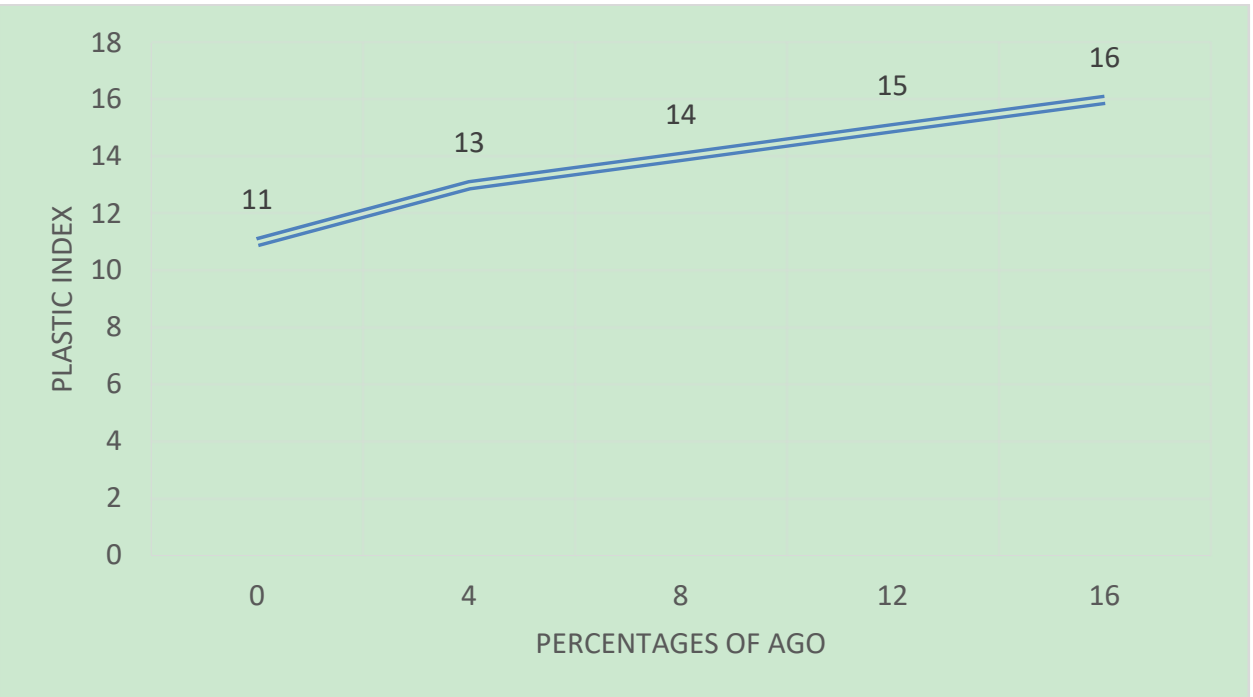

Figure 5: Graph of Plastic Index against Automotive Gas oil

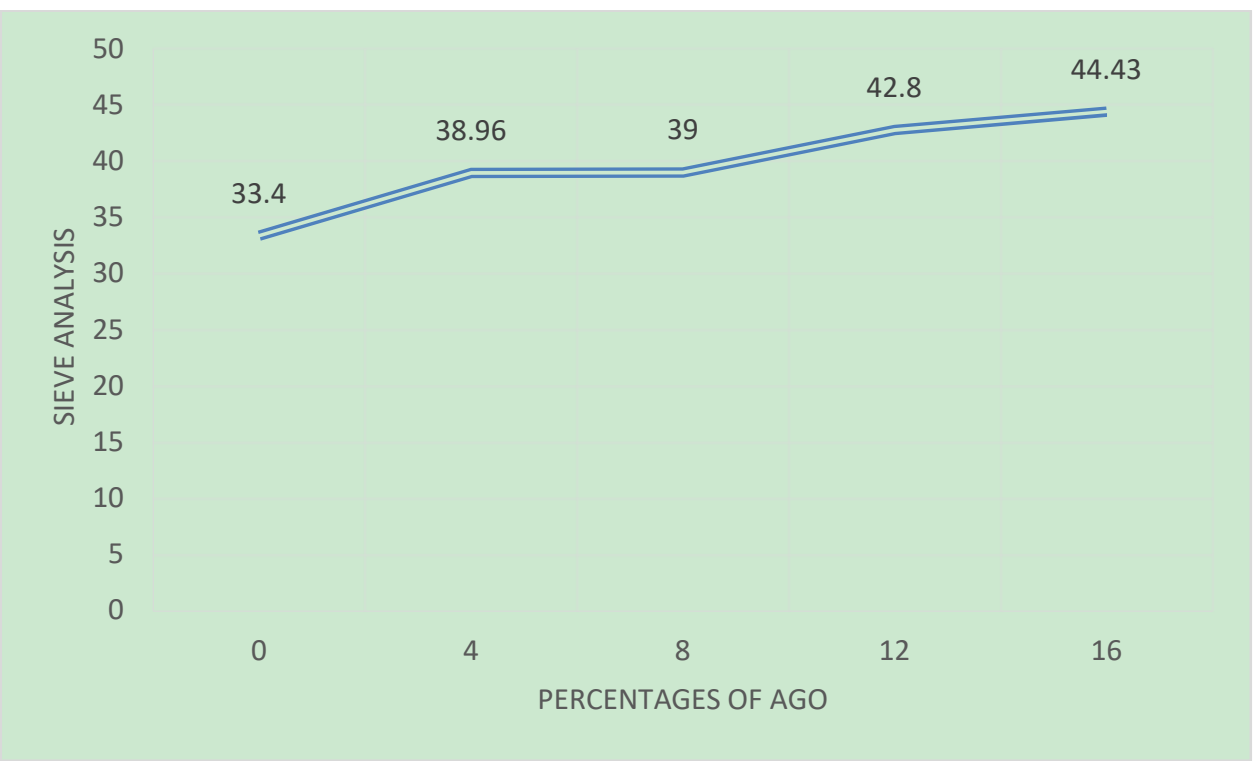

Figure 6: Graph of Sieve Analysis against Automotive Gas oil

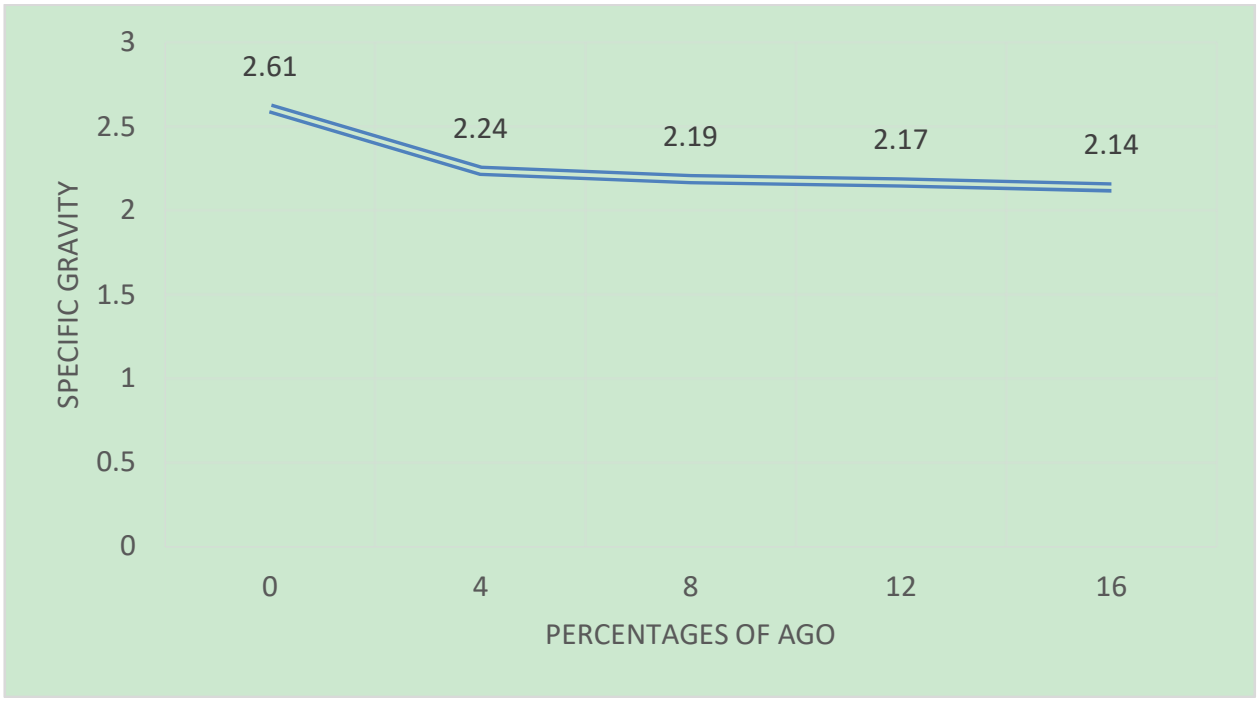

Figure 7: Graph of Specific Gravity against Automotive Gas oil 


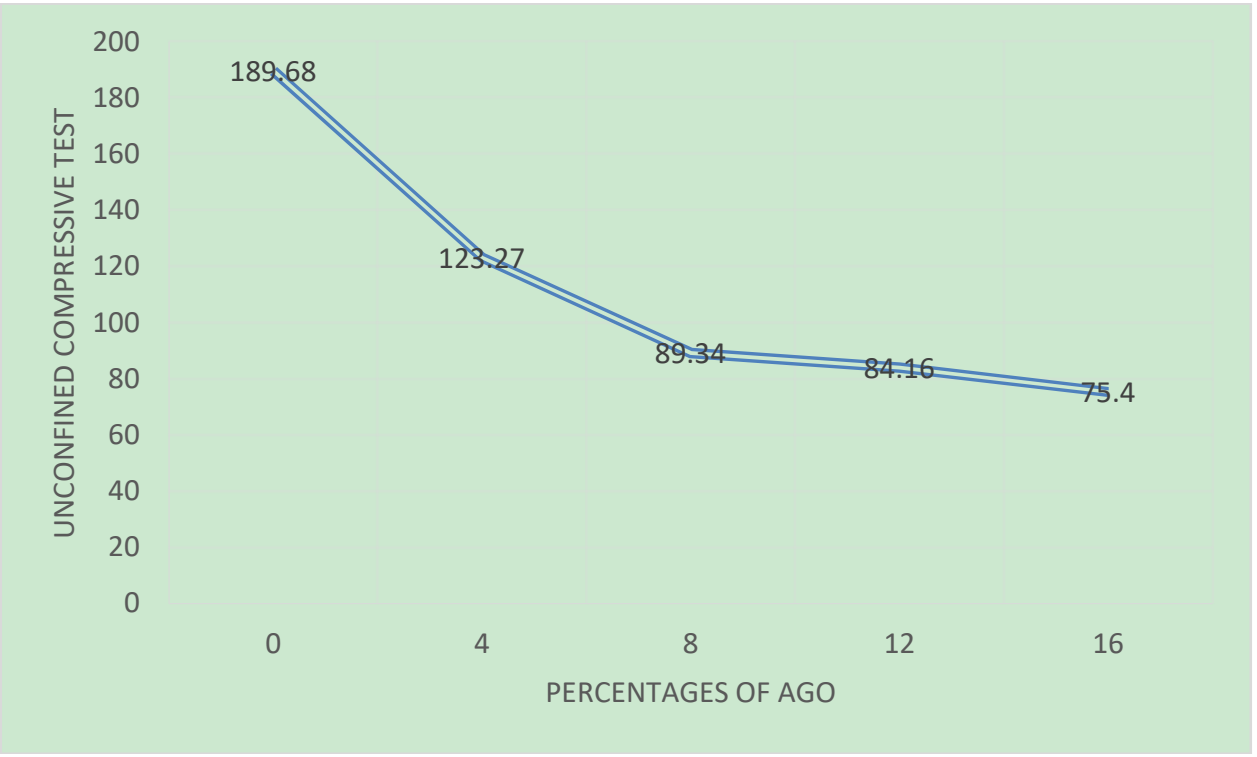

Figure 8: Graph of Unconfined Compressive Test against Automotive Gas oil

The liquid limits, which is a basic measure of the critical water content of soil, increased as the percentage of AGO increased with the highest value of $42.00 \%$ obtained at $16 \%$ AGO (Figure 3). The uncontaminated lateritic soil has liquid limits of $34 \%$ which falls within the recommended limit of soil for construction. Plastic limits also increased as the percentage of AGO increased (Figure 4). The uncontaminated (0\% AGO) soil has the least percentage value of plasticity index $(11.00 \%)$, while the highest value $(16.00 \%)$ was obtained at $16 \%$ AGO (Figure 5).

We also obtained that Sieve analysis increased as the percentage of AGO increased, recording the highest value $(44.43 \mathrm{~mm})$ at $16.00 \%$ AGO (Figure 6). Specific gravity was found to decrease as the percentage of contamination increased (Figure 7); and the unconfined compressive test decreased as the percentage of contamination increased (Figure 8).

These results are consistent with those obtained in published literature (Ukpong and Umoh, 2015; Onyelowe, 2015; Jesna and Hari, 2015; Otonyo and Anele, 2015; Akinwimi et al., 2014).

\section{Conclusion}

The study reveals that increased plasticity indicates that contamination of soil made it less workable. Utilisation of the contaminated soil without stabilization or remediation as a construction material is not encouraged. Addition of AGO to the soil lead to reduction of porosity and permeability resulting from the entrapment of the AGO within the pore spaces of the soil.

\section{References}

Ijimdiya, T. S. (2013). The Effects of Oil Contamination on the Consolidation Properties of Lateritic Soil. Development and Applications of Oceanic Engineering (DAOE), Vol. 2(2):53-59.

Onyelowe, K. C. (2015). Pure Crude Oil Contamination on Amaoba Lateritic Soil. International Journal of Engineering Research and Technology, Vol. 20(3):1129-1142.

Otunyo, A. W. and Anele, O. (2015). Effect of Waste Engine Oil Contamination on Geotechnical Properties of Clay Soil. European International Journal of Science and Technology, Vol. 4(8): 28-38.

Afolabi, O. A., Adeyemi, S. A. and Imevbore, A. M. A. (1985). "Studies on Toxicity of some Nigerian Crude Oils to some Aquatic Organisms". In Proceedings of 1985 International Seminar on Petroleum Industry and the Nigerian Environment. Federal Ministry of Works and Housing, Kaduna, pp. 269-272.

Al-Sanad, H. A., Eid, W. K. and Ismael, N. F. (1995). Geotechnical Properties of Oil- Contaminated Kuwaiti Sand. Journal of Geotechnical Engineering, Vol. 5: 407-412.

Alhassan, H. M. and Fagge, S. A. (2013). Effects of Crude Oil, Low Point Pour Fuel Oil and Vacuum Gas Oil Contamination on the Geotechnical Properties of Sand, Clay and Lateritic Soils. International Journal of Engineering Research and Applications, Vol. 3(1): 1947-1954.

Jesna, J. and Hari, G (2015). Investigation on the Effects of Hydrocarbon Spillage on Soil properties. International Journal of Engineering Research and Technology, Vol. 4(10): 136-140.

Akinwumi, I. I., Diwa, D. and Obiangwe, N. (2014). Effects of Crude Oil Contamination on the Index Properties, Strength and Permeability of Lateritic Clay. Int. Journal of Applied Sciences and Engineering Research, Vol. 3(4): 816-824. 
Ukpong, E. C. and Umoh, I. C. (2015). Effect of Crude Oil Spillage on Geotechnical Properties of Lateritic Soil in Okoroete, Eastern Obolo. International Journal of Engineering and Applied Sciences, Vol. 7(1): 12-24.

Rahman, Z. A., Hamzah, U., Taha, M. R., Ithnain, N. S., and Ahmad, N. (2010). Influence of Oil Contamination on Geotechnical Properties of Basaltic Residual Soil. American Journal of Applied Sciences, 7(7): 954-961.

Colorado Department of Public Health and Environment, (2003). Monitoring and Removal or Treatment of Contamination Soil Colorado State, USA. 